\title{
To Identify the Prevalence Leptospira Serogroups in the Cases From Southern Gujarat Region
}

\section{TANVI PANWALA, SUMMAIYA MULLA}

\begin{abstract}
Introduction: Leptospirosis, is a widespread zoonosis which affects the human worldwide. It is an acute febrile illness; the severity varies from mild to severely fatal form. Because of protean clinical manifestation and unavailability of appropriate laboratory diagnostic facilities in most part of the country, human cases has been reported less in India. Clinically leptospirosis shows, similar signs and symptoms with other diseases which mandate the need of laboratory confirmation.
\end{abstract}

Aim: To identify prevalent circulating serogroups in human cases of South Gujarat region by performing Microscopic Agglutination Test (MAT) and to compare results of commercially available IgM Enzyme-Linked Immunosorbent Assay (ELISA) with MAT.

Settings and Design: A retrospective cross sectional study.
Materials and Methods: A total of 157 serum samples were collected from suspected leptospirosis patients and subjected to serological tests like MAT and IgM-ELISA. Identification of predominant infecting serogroup was done by using panel of 11 serovars.

Statistical Analysis Used: Sensitivity and specificity.

Results: MAT analysis of 157 samples showed 113(72\%) to be positive. Antibodies were predominantly against serogroups like Leptospira autumnalis $(60 \%)$, L. australis $(16 \%)$ and $L$. pyrogenes $(7 \%)$. IgM-ELISA showed a positivity of $74 \%$ compared to MAT.

Conclusion: L. Autumnalis is the predominant serovar identified in the present study so MAT can be used as a gold standard in conjunction with an IgM-ELISA in diagnostic laboratories.

\section{INTRODUCTION}

Leptospirosis is a widespread zoonosis which affects the human worldwide. It is an acute febrile illness; the severity varies from mild to severely fatal form. The causative bacteria, Leptospira species, are responsible for a wide spectrum of clinical symptoms due to which disease is often misdiagnosed [1,2], particularly in tropical countries. Because of its protean clinical manifestation, confirmatory diagnosis is based on laboratory tests rather than on clinical symptoms alone [3]

Suitability of environmental condition for survival of Leptospira A appears to be critical factor in maintaining the infection. Leptospira A have good affinity to areas where heavy rainfall resulted in water logging of land so human leptospirosis is more prevalent in several states of India like Gujarat, Maharashtra, Karnataka, Kerala, Tamil Nadu, and Andaman Nicobar islands where survival of bacteria is possible. The cases are either sporadically or as out breaks, especially during rainy seasons [4-10]. In general, the two contributing factors for the gross under-reporting of leptospirosis cases include difficulty in clinical diagnosis and the lack of simple diagnostic measures for early detection of the infection during the acute phase. The disease symptoms may vary from mild flu like illness to wide variety of clinical syndromes including hepatic failure, renal failure, jaundice, severe pulmonary haemorrhage, disseminated intravascular coagulation (DIC) and meningitis $[11,12]$. Direct detection of the organism from clinical material by culture gives definite proof of the diagnosis but it is a time consuming procedure requiring expensive laboratory facilities and the success rate is very low [2]. Molecular methods, mainly polymerase chain reaction assays (PCR) cannot be used as a sole diagnostic test because these tests require expensive equipment and expertise and false positivity rate is also there [13]. Various Serological tests which detect agglutinating antibodies against leptospira remain the most practical method for diagnosis of leptospirosis. So, aim of present study was to identify prevalent circulating serogroups in human cases from Southern Gujarat region and to compare results of commercially available IgM enzyme-linked immunosorbent assay (ELISA) with MAT. 


\section{MATERIALS AND METHODS}

It was a retrospective cross sectional study. One hundred fifty seven blood samples from suspected leptospirosis patients (according to WHO case definition) were received in Microbiology Department, Government Medical College, Surat, Gujarat India. Samples were collected from suspected patients that admitted in New Civil Hospital, a tertiary health centre of South Gujarat during period from July 2012December 2012 who presented clinically with signs or symptoms of leptospirosis like abrupt onset of fever, myalgia, headache, oliguria, breathlessness, haemoptysis, jaundice, acute renal failure, bleeding tendency, meningism etc. Patient having other infection like malaria, dengue, hepatitis, typhoid etc., that diagnosed by laboratory was excluded from the study. All sera were stored at $-20^{\circ} \mathrm{C}$ and further subjected to MAT and IgM ELISA. Informed consent was taken from all human participants and study was approved by Human Research Ethics Committee, Government Medical College, Surat, Gujarat for research purpose.

\section{MAT}

The MAT test was performed using standard procedure [14]. Live Leptospira representing 11 serovars belonging to 11 serogroups were used in MAT test. Serogroups included in the antigen panel of MAT test are as follows: L.pyrogenes (Pyrogen), L.australis (Australis), L.autumnalis (Bangkinang), L.grippotyphosa (Grippotyphosa), L.semerang (patoc), L.pomona (Pomona), L.ballum (Ballum), L. sejroe (Hardjo), L.canicola (Canicola), L.hebdomadis (Hebdomadis), L.icterohaemorrhagiea (Icterohaemorrhagiea). All the strains were procured from the National Leptospirosis Reference Centre, Regional Medical Research Centre (World Health Organization collaborating centre for diagnosis in leptospirosis, ICMR) in Port Blair, Andaman and Nicobar islands. These serovars were maintained in $0.1 \%$ semisolid EMJH agar base medium supplemented with 10\% enrichment (Diffco, USA) at $28-30^{\circ} \mathrm{C}$ in screw-capped test tubes for long time preservation.

$0.5 \mathrm{ml}$ of these representative strains from the panel of 11 serovars were inoculated into $10 \mathrm{ml}$ of liquid $\mathrm{EMJH}$ (Ellinghausen- McCullough- Johnson-Harris medium) supplemented with 10\% enrichment (Diffco,USA). These screw capped test tubes were kept in Incubator at $28-30^{\circ} \mathrm{C}$ for five to seven days. Culture was checked after 5 days under dark field microscopy to see that absence of any contamination or clumps and presence of enough quantity of viable leptospires. A density of approximately $2-3 \times 10^{8}$ leptospires $/ \mathrm{ml}$ of media was used as an antigen in MAT test.

\section{Procedure of MAT test}

Doubling dilutions of serum from 1 in 25 to 1 in 6400 were prepared by adding PBS (Phosphate buffered solution) in
96 well flat bottomed microtitre plates. Fifty micro liters of live Leptospira cell suspension were added to serially diluted serum specimens and incubated at $37^{\circ} \mathrm{C}$ for 2 hours. One of the wells included only the antigen without addition of antibody and served as the antigen control. The final dilutions after adding the antigen were from 1 in 50 to 1 in 12800. The reported titre was calculated as the reciprocal of the highest dilution that agglutinated at least $50 \%$ of the cells for each serovar or a reduction in the number of leptospiral cells as compared to the antigen control was taken as end point titer. A titer of 1 in 100 or more was considered significant.

\section{IgM ELISA Test}

Whole procedure was performed according to manufacturer's instruction. Leptospira biflexa serovar patoc antigen attached to polystyrene surface of micro well test strips and $10 \mu \mathrm{l}$ of test serum added to this well. Plates were incubated for $30 \mathrm{~min}$ at $37^{\circ} \mathrm{C}$. HRP-conjugated anti-human IgM and the TMB in the kit were added in subsequent steps as per manufacturer's instruction. Absorbance was read at 450nm and reading was interpreted in terms of Pan-Bio units. The absorbance of positive control serum, negative control serum and cut-off of calibrators provided by the manufacturer were used for the calculation of Pan-Bio units. Samples were considered as positive if the number of Pan-Bio units were more than 11 [15].

\section{Criteria for Laboratory Confirmation}

If any sera showed fourfold or greater rise of antibodies titre in MAT test between acute and convalescent phase serum, was considered as a confirm case of leptospirosis.

\begin{tabular}{|c|c|c|c|}
\hline \multirow{2}{*}{$\begin{array}{l}\text { Serological } \\
\text { Test }\end{array}$} & \multicolumn{2}{|c|}{ Leptospirosis } & \multirow[t]{2}{*}{ Total } \\
\hline & $\begin{array}{c}\text { Present } \\
\text { (Mat Positive) }\end{array}$ & $\begin{array}{c}\text { Absent } \\
\text { (Mat Negative) }\end{array}$ & \\
\hline IgM ELISA Positive & 107 & 9 & 116 \\
\hline IgM ELISA Negative & 6 & 35 & 41 \\
\hline Total & 113 & 44 & 157 \\
\hline \multicolumn{4}{|c|}{$\begin{array}{l}\text { [Table/Fig-1]: Sensitivity and specificity of IgM ELISA test. } \\
\text { Sensitivity of IgM ELISA: } 94 \% \text { Positive Predictive value: } 92 \% \\
\text { Specificity of IgM ELISA: } 80 \% \text { Negative Predictive value: } 85 \% \\
p=0.0001 \text { (<0.05, so it is significant) }\end{array}$} \\
\hline
\end{tabular}

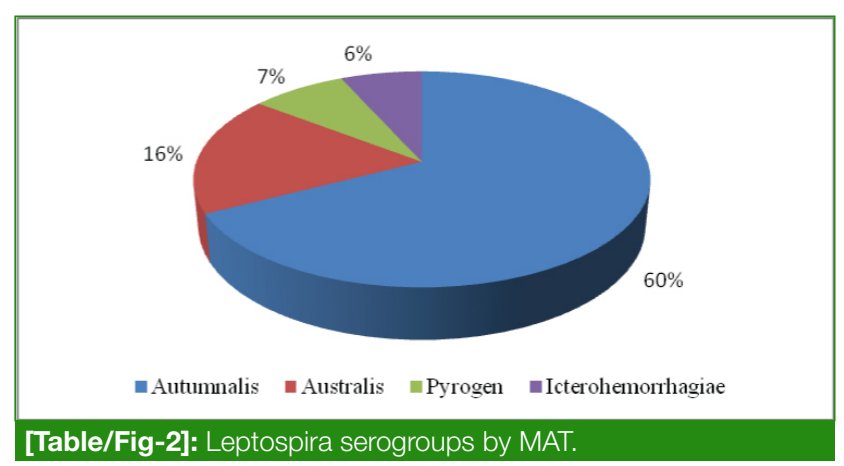




\begin{tabular}{|c|c|c|c|c|c|c|c|c|}
\hline Titer & Autumnalis & Australis & Pyrogen & Icterohemorrhagiae & Pomona & Gripphotyphosa & Hebdomadis & Canicola \\
\hline $1: 100$ & 7 & 0 & 0 & 0 & 0 & 0 & 0 \\
\hline $1: 200$ & 3 & 2 & 1 & 1 & 0 & 0 & 0 \\
\hline $1: 400$ & 15 & 6 & 4 & 1 & 1 & 1 & 0 & 1 \\
\hline $1: 800$ & 21 & 8 & 2 & 2 & 3 & 1 & 0 \\
\hline $1: 1600$ & 9 & 3 & 1 & 0 & 1 & 0 & 0 \\
\hline $1: 3200$ & 9 & 0 & 0 & 1 & 0 & 0 & 0 & 0 \\
\hline $1: 6400$ & 4 & 0 & 0 & 0 & $\mathbf{6}$ & $\mathbf{2}$ & 0 & 0 \\
\hline Total & 68 & 19 & 8 & 7 & & $\mathbf{1}$ \\
\hline
\end{tabular}

\section{RESULTS}

Out of the 157, 122 (77\%) sera were positive for antileptospiral antibodies either by MAT or ELISA. These 122 positive cases included 73 males and 49 females indicating a male preponderance. The highest seropositivity was observed between 25 and 65 years of age suggesting that this age group was involved more in outdoor activities.

Out of $157113(72 \%)$ suspected cases showedanti-leptospiral antibodies by MAT [Table/Fig-1] with the L.Autumnalis (60\% samples) as a predominant serogroup followed by L. australis (16\%) and L.pyrogenes (7\%) [Table/Fig-2]. The other serovars observed were L.Icterohemorrhagiae (6\%), L. pomona (5\%), L. grippotyphosa (1\%), L. hebdomadis (1\%) and L. canicola (0.8\%). Serovar L. hardjo and L.Ballum did not show any significant titer in MAT test. A titer of 100 or more was considered to be significant [Table/Fig-3]

Sixty three (56\%) samples showed antibody titer between 1 in 400 to 1 in 800. [Table/Fig-3], shows the distribution of titers among the MAT positive samples. It was observed that the highest antibody titer was recorded against serovar $L$. autumnalis, 1 in 6400.

IgM ELISA was also performed on the 157 serum samples and 116 (74\%) were found to be positive. The comparison between results of IgM ELISA and MAT is shown in [Table/ Fig-1]. 113 samples out of the 157 (72\%) reacted positively by MAT with a titre of $\geq 1: 100$. In 107 (68\%) cases both MAT and IgM ELISA were positive. The sensitivity of IgM ELISA when compared to MAT was $94 \%$. In 9 patients in this study, IgM ELISA was positive but the diagnosis could not be confirmed by MAT. By applying the Chi square test, the $p$ value is $0.0001(<0.05$ so it is significant) which shows that there is association between IgM ELISA and MAT test results.

\section{DISCUSSION}

It is known that leptospirosis is widespread zoonotic disease in warm and humid climate of tropical and sub-tropical region in many parts of India including the north-east, West Bengal,
Bihar, Madhya Pradesh, Maharashtra, Andhra Pradesh, Karnataka, Kerala, Tamil Nadu, Punjab and Haryana [16]. The preponderance of cases in males between 25 and 65 years of age shows that this disease is more prevalent among the occupational groups who are most likely to be exposed to this organism [17-22].

It is reasonable now to believe that leptospirosis is a common cause of acute febrile illness in South Gujarat and it is a continuing problem in this part of the country. Early diagnosis and treatment is essential. If untreated the illness can progress rapidly and mortality rates are high in severe cases. It is therefore important to differentiate leptospirosis from other causes of acute febrile illnesses. The reason for high prevalence of leptospirosis in South Gujarat zone may be due to the overuse of fertilizers for agricultural activity, which makes the $\mathrm{pH}$ of the water and soil alkaline, thereby allowing Leptospira to survive for a longer time and thus facilitating its transmission [23].

IgM antibodies can earliest be detected few days after the onset of symptoms. These antibodies are detectable in all patients up to five months after infection. From the clinical point of view, the ability to detect the infection early in the course of the disease is of extreme importance for initiating appropriate treatment to avoid serious complications. In this context, the genus specific lgM immunoassays would be of great use for detecting Leptospirosis at an early stage of the disease. IgM ELISA testing can be developed at district level laboratory with ELISA reader and washer equipment.

The MAT is the gold standard test for serological diagnosis and classification. MAT test detects both $\lg M$ and $\lg G$ antibodies in the patient's sera so; if agglutinating antibodies is observed by doing MAT test in a single serum sample, it does not necessarily prove current Leptospirosis. An antibody titre may be due to residual antibodies if patient was exposed previously to leptospirosis infection. Therefore, the interpretation of a single titre is not easy; a second serum sample is required for demonstrating a rising titre which will helpful for confirmation of diesase. The main advantage of 
MAT test is serovar/serogroup specific test though crossreactivity happens; some clue about the infecting serovar can be obtained. It is sensitive and has excellent specificity. Once infected, the person stays MAT positive for several years. So, the test is useful for epidemiological purpose.

In the present study, predominant infecting serovar observed was L.autumanalis (60\%), as in Ratnam study have also reported L.autumnalis in Chennai, Cumbum, Tirunenveli Panama in Madurai [24] while L.icterohemorrhagiae was predominant strain in Mumbai [25], Pune [26] and in Pondicherry [27]. L.grippotyphosa was found as the predominant serogroup in Andaman Island [28] and Kerala [5].

IgM ELISA is a genus specific test and detects IgM antibodies against the serovar patoc in the acute phase of disease, which will help in timely treatment of leptospirosis cases. MAT is a serogroup/serovar specific test which detecting both IgG and IgM against different species of leptospira. False negative results can obtained in MAT test because of agglutinating antibodies usually appear in detectable levels only at the end of the first week. In present study, IgM ELISA showed overall positivity of 92\%. The individual positivity rates of both the tests were less than their combined efficacy. MAT done in this study enabled us to know the prevalent serogroups.

\section{LIMITATION}

The limitation of present study is that MAT test is not used as routine investigation because MAT test has many disadvantages which suggest the need of an alternative test. MAT test requires 14-21 live strains of Leptospirosis that to be maintained in culture continuously which is often very difficult, complex and time consuming. Handling of these hazardous bacteria in laboratories and reading the results of MAT test is also subjective requires, experienced personnel.

\section{CONCLUSION}

Leptospirosis is globally relevant infectious disease associated with high mortality rate. Clinical diagnosis along with Laboratory confirmation of leptospirosis cases is beneficial for patients to institute early treatment to improve outcome. L.autumnalis have emerged as the infecting circulating serovar in South Gujarat region. As shown in this study, both tests are feasible and can be standardised for routine testing in research laboratories. In our opinion a combination of IgM ELISA and MAT offered the most reliable laboratory strategy for confirmation of leptospirosis.

\section{REFERENCES}

[1] Heath CWJ, Alexander AD, Galton MM. Leptospirosis in the United States: Analysis of 483 cases in Man. N Eng $J$ Med. 1965;273: 857-64.

[2] Faine S. Guidelines for the control of leptospirosis. WHO Offset Publication: 1982.No. 67, Geneva.
[3] Bal AE, Gravekamp C, Hartskeerl RA, de Meza-Brewster J, Korver K, Terpstra WJ. Detection of leptospires in urine by PCR for the early diagnosis of leptospirosis. J Clin Microbiol. 1994;8: 1894-98

[4] John Tj. The prevention and control of human leptospirosis. $J$ Post grad Med. 2005; 51:205-09.

[5] John TJ. Emerging and re emerging bacterial pathogens in India. Indian J Med Res. 1996;103: 4-18.

[6] Natarajaseenivasan K, Boopalan M, Selvanaayaki K, Suresh SR, Ratnam S. Leptospirosis among rice mill workers of Salem, South India. Jpn J Infect Dis. 2002;55:170-73.

[7] Sehgal SC. Leptospirosis in the horizon. Natl Med J India. 2000;13: 228-30.

[8] Sehgal SC. Emergence of Leptospirosis as a public health problem. In: Leptospirosis. Proceedings of the third Round Table Conference, New Delhi”. Singhal RL, Sood OP, editors. Ranbaxy Science Foundation: Gurgaon. 1998; p. 7-16.

[9] Ratnam S, Sundarraj T, Subramanian. Serological evidence of leptospirosis in a human population following an outbreak of the disease in cattle. Trans Royal Soc Trop Med Hyg. 1983;77:9498.

[10] Ratnam S. Leptospirosis: An Indian perspective. Indian J Med Microbiol.1994;12:228-39.

[11] Bharti AR, Nally JE, Ricaldi JN, Matthias MA, Diaz MM, Lovett MA. Leptospirosis: A zoonotic disease of global importance. Lancet Infect Dis. 2003;3:757-71.

[12] Patil VC, Patil HV, Agrawal V. Clinical profile and outcome of leptospirosis at tertiary care centre in western Maharashtra. $J$ Acad Med Sci. 2012; 2: 30-37.

[13] Levett PN. Leptospirosis. Clin Microbiol Rev. 2001;14: 296326.

[14] Vijayachari P, Suganan AP, Sehgal SC. Role of microscopic agglutination test (MAT) as a diagnostic tool during acute stage of leptospirosis in low and high endemic areas. Indian J Med Res. 2001;114: 99-106.

[15] Bajani MD et al. Evaluation of four commercially available rapid serologic tests for diagnosis of leptospirosis. J of Clinical Microbiol. 2003, 803-09.

[16] Velineni S, Asuthakar S, Umbala P, Lakshmi V, Sritharan M. Serological evaluation of leptospirosis in Hyderabad, Andhra Pradesh: A retrospective hospital- based study. Indian J Med Microbiol. 2007;25(1): 24-27.

[17] Mansour-Ghanaei F, Sarshad All, Fallah MS, Pourhabibi A, Pourhabibi K, Yousei-Mashhoor M. Leptospirosis in Guilan, a northern province of Iran: assessment of the clinical presentation of 74 cases. Med Sci Monit. 2005; 11:219-23.

[18] Costa E, Costa YA, Lopes AA, Sacramento E, Bina JC. Severe forms of leptospirosis: clinical, demographic and environmental aspects. Rev Soc Bras Med Trop. 2001; 34: 261-67.

[19] Daher EF, Zanetta DM, Cavalcante MB, Abdulkader RC. Risk factors for death and changing patterns in leptospirosis acute renal failure. Am J Trop Med Hyg. 1999; 61:630-34.

[20] Daher EF, Zanetta DM, Abdulkader RC. Pattern of renal function Recovery after leptospirosis acute renal failure. Nephron Clin Pract. 2004; 98:8-14.

[21] Katz AR, Ansdell VE, Efler PV, Middleton CR, Sasaki DM. Assessment of the clinical presentation and treatment of 353 cases of laboratory confirmed leptospirosis in Hawaii. Clin Inf Dis. 2001; 33:1834-41.

[22] Jauréguiberry $S$, Roussel M, Brinchault-Rabin G et al. Clinical Presentation of leptospirosis: a retrospective study of 34 patients admitted to a single institution in metropolitan France. Clin Microbiol Infect. 2005; 11:391-94. 
[23] Diesch SL, McCullochWF, Braun JL, CrawfordRP. Environmental studies on the survival of leptospires in a farm creek following a human leptospirosis outbreak in lowa. Proc Ann Conf Bull Wildlife Disease Assoc. 1969;5: 166-73.

[24] Ratnam S, Everard CO, Alex JC, Suresh B, Muthusethupathi MA, Helen Manual PS. Leptospiral antibodies among human beings in Tamil Nadu. Indian J Med Microbiol. 1993; 11:203-05.

[25] Bharadwaj RS, Bal AM, Joshi SA, Kagal AS, Pol SS, Garad G. An urban outbreak of leptospirosis in Mumbai, India. Jpn J Infect Dis. 2002 55: 194-96.
[26] Bal AM, Bharadwaj RS, Joshi SA, Kagal AS, Arjunwadkar VP. Common infecting serovars in and around Pune, Maharashtra. Indian J Med Res. 2002;115: 14-16.

[27] Shekatkar SB, Harish BN, Menezes GA, Parija SC. Clinical and serological evaluation of leptospirosis in Puducherry, India. J Infect Dev Ctries. 2010;4(3):139-43.

[28] Sehgal SC, Murhekar MV, Sugunan AP. Outbreak of leptospirosis with pulmonary involvement in North Andaman. Indian J Med Res. 1995; 102: 9-12.

\section{AUTHOR(S):}

1. Dr. Tanvi Panwala

2. Dr. Summaiya Mulla

\section{PARTICULARS OF CONTRIBUTORS:}

1. Assistant Professor, Department of Microbiology, Government Medical College, Surat, Gujarat, India.

2. Professor and Head, Department of Microbiology, Government Medical College, Surat, Gujarat, India.

\section{NAME, ADDRESS, E-MAIL ID OF THE} CORRESPONDING AUTHOR:

Dr. Tanvi Panwala,

E-7, Vighneshwar Estate, Nanpura,

Timaliavad, Surat-395001, Gujrat, India.

E-mail: drtanvi2006@yahoo.co.in

FINANCIAL OR OTHER COMPETING INTERESTS:

None. 